\section{An investigation into senior high school students' understanding and difficulties in writing chemical formulae of inorganic compounds}

\author{
Baah, Rexford $\measuredangle$ \\ Department of Science \& Mathematics Education, University of Cape Coast, Ghana (rexfordbaah@yahoo.com) \\ Anthony-Krueger, Christian \\ Department of Science \& Mathematics Education, University of Cape Coast, Ghana (kruegertony@yahoo.com)
}

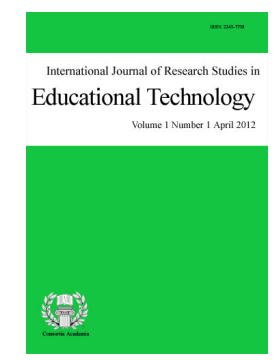

ISSN: 2243-7738 Online ISSN: 2243-7746

OPEN ACCESS

\title{
Abstract
}

Students' inability to write correct chemical formulae has for some time been a source of worry to the West African Examinations Council, the body responsible for organizing examinations in West Africa. Learning how to write chemical formulae is a vital area for one to progress in the study of chemistry and it is one of the exercises that give a lot of fascination and challenge to young chemists starting to learn chemistry. This study probed into the difficulties students have in writing correct chemical formulae from IUPAC names. The study used a cross-sectional survey using both quantitative and qualitative methods. The sample used for the study consisted of 334 SSS 3 elective science students for 2008/2009 academic year drawn from all the schools that offer elective science in the New Juaben Municipality of the Eastern Region of Ghana. The instruments used for data collection were achievement test and interview. Some of the key findings about students' difficulties in writing chemical formulae from IUPAC names were: students lack of understanding of the Roman numerals that are put in brackets of IUPAC names, students difficulty in knowing what valencies are and the role they play in writing chemical formulae, students inability to write the correct formulae of some radicals and ions and inability to determine the cations and anions of ionic compounds and hence inability to combine certain cations and anions to form neutral compounds due to lack of knowledge about valency.

Keywords: chemical symbol; science; senior high school; learning difficulties; mixed-method study 


\section{An investigation into senior high school students' understanding and difficulties in writing chemical formulae of inorganic compounds}

\section{Introduction}

A chemical formula is a combination of elemental symbols and subscript numbers that is used to show the composition of a compound. It is a shorthand method for representing a chemical compound. A formula consists of a collection of chemical symbols, telling the kinds and numbers of atoms present in the compound. Today the rules for writing chemical formulae are set by the Nomenclature Committee of the International Union of Pure and Applied Chemistry (IUPAC) and chemical formulae that follow the rules of this committee are said to follow IUPAC nomenclature.

Studies conducted by Savoy (1988) and Hines (1990) have revealed that students have difficulties in writing chemical formulae. In his early study, Johnstone (1974) reported that the problem areas in chemistry, from pupils' point of view, persisted well into university education with the most difficult topics being chemical formulae among other topics. The findings from the research of Lazonby, Morris, and Waddington (1982), Schmidt (1984) and Bello, (1988) have shown that students' persistent difficulties in solving stoichiometric problems are partly associated with their inability to write chemical formulae correctly. While, a study conducted by Anamuah - Mensah and Apafo (1986) revealed that students in Ghanaian Senior High Schools have difficulties in learning certain chemical concepts such as chemical combination. According to the study, about $66 \%$ of the respondents indicated that the topic chemical combination was either difficult to grasp or never grasped.

Reports by the chemistry Chief Examiners' (CE) available at the West African Examinations Council (WAEC) also attest to the fact that students have difficulty in writing chemical formulae. In 1994, the CE report for Senior Secondary School Certificate Examination (SSSCE) in chemistry stated that Sodium trioxocarbonate (IV) and Sodium hydrogen trioxocarbonate (IV) were badly written by students as $\mathrm{NACO}$ and $\mathrm{NA}_{2} \mathrm{HCO}_{3}$ respectively. Also the $2001 \mathrm{CE}$ report said that writing of chemical formulae was poorly handled by candidates. The 2004 chemistry theory paper required candidates to write a balanced chemical equation for the production of oxygen when $\mathrm{KClO}_{3}$ is heated and then calculate the volume of dry oxygen gas evolved. The examiners' CE report on the above question was that candidates had problems writing the equation correctly. This was partly due to their inability to predict and write the correct formulae of the products hence they could not get the correct mole ratio. Then in 2005, a summary of candidates' weaknesses of the CE report indicated that candidates had problems writing correct chemical formulae of substances. Hence, one can easily say that students really have problems in writing chemical formulae of substances. Secondly, considering the fact that very little research has been done in this area, makes the study an important one.

The purpose of this study was to probe students' understanding and difficulties in writing of chemical formulae from IUPAC names. The study also compared the performances of students from both well endowed and less endowed schools so as to know where the difficulty is more conspicuous. The study therefore attempted to answer the following research question:

$>\quad$ What difficulties do SSS 3 students' have in writing chemical formulae from IUPAC names?

The following null hypothesis was also tested to guide the study:

There is no significant difference between the performance of students from well-endowed and less-endowed schools in writing chemical formulae from IUPAC names. 


\section{Methodology}

The study attempted to investigate how students understand the writing of chemical formulae from IUPAC names and the difficulties they have in doing so. Cross-sectional survey was used to accomplish this. The design of the study involved two stages in which mixed methods quantitative and qualitative techniques were used to collect data. In order to develop the instrument, the items were constructed by the authors and administered to SSS 3 elective science students of the University Practice Senior High School, Cape Coast, Ghana; a school which was not used in the main study. The responses from the students were used as a guide to construct the achievement test. The achievement test was shown to chemistry lecturers in the Department of Science and Mathematics Education, University of Cape Coast, Ghana for them to determine the validity of the instrument and offer suggestions. The instrument was pilot-tested using a sample of 54 elective science students drawn from Ofori Panyin Senior High School in Tafo in the Eastern Region of Ghana. The Statistical Package for Social Sciences (SPSS) was used to determine the Cronbach alpha coefficient of reliability for the items in the chemical formulae test and an alpha value of 0.90 was obtained. The difficulty and discrimination index for each item was determined and items found to be too difficult or too easy or bad were deleted.

In the first stage, achievement test (comprising 6 items, Qa. Copper (I) oxide, Qb. Iron (II) sulphide, Qc. Copper (II) tetraoxophosphate (V), Qd. Calcium trioxonitrate (V), Qe. Ammonium trioxocarbonate (IV), Qf Silver nitride) on writing of chemical formulae was administered to SSS 3 elective science students drawn from all seven Senior Secondary Schools (SSS) offering science as elective in the New Juaben Municipality of the Eastern Region of Ghana. The second stage involved group interviews of students who got the items wrong. The interview was conducted to ascertain their reasons for getting the items wrong. The instruments were administered to the students in their various schools.

The target population for this study was all SSS 3 students offering elective science for the 2008/2009 academic year in the New Juaben Municipality of the Eastern Region of Ghana. These students have studied chemistry for almost three years and therefore could make meaningful contribution to the study. The schools which were seven in number were classified as well-endowed and less-endowed based on two reasons; one is the science facilities the school has and the other is the grade with which students are admitted to do science in the schools. The sample consisted of 334 SSS 3 elective science students. The mean age of the students was 17 years with a standard deviation of 1.8 years. The sample was drawn from all the schools in the population. Table 1 shows the number of science students who were present in their respective schools at the time of the study and participated in the study. Table 2 also shows the gender of the students in their respective schools.

Table 1

Number of students in the various schools that participated in the study

\begin{tabular}{cc}
\hline Schools & Number and Percentage of students who participated in the study \\
\hline A & $70(58.3 \%)$ \\
B & $30(88.2 \%)$ \\
C & $80(58.9 \%)$ \\
D & $55(51.0 \%)$ \\
E & $42(97.7 \%)$ \\
F & $35(100.0 \%)$ \\
G & $22(56.4 \%)$ \\
\hline
\end{tabular}

\section{Results and discussions}

Percentages was used to explain the performance of students in the test and the independent samples t-test analysis was used to test for difference in performance of students from well-endowed and less-endowed schools. The independent samples t-test analysis was used because the two groups (well-endowed and less-endowed 
Baah, R. \& Anthony-Krueger, C.

schools) were independent of each other and scores from the two groups were normally distributed. Qualitative data gathered during interviews was transcribed and used as an explanation of students answers provided in the tests. The performance of the students according to schools is shown in table 3 .

Table 2

Gender of students in the various schools that participated in the study

\begin{tabular}{crr}
\hline Schools & \multicolumn{1}{c}{ Male students } & Female students \\
\hline A & $61(87.1 \%)$ & $9(12.9 \%)$ \\
B & $19(63.3 \%)$ & $11(36.7 \%)$ \\
C & $50(62.5 \%)$ & $30(37.5 \%)$ \\
D & $55(100.0 \%)$ & $0(0.0 \%)$ \\
E & $26(61.9 \%)$ & $16(38.1 \%)$ \\
F & $24(68.6 \%)$ & $11(31.4 \%)$ \\
G & $17(77.3 \%)$ & $5(22.7 \%)$ \\
Total & $252(75.4 \%)$ & $82(24.6 \%)$ \\
\hline
\end{tabular}

Table 3

Schools Performance on Writing of Chemical Formulae of Inorganic Compounds

\begin{tabular}{|c|c|c|c|c|c|c|}
\hline Schools & Qa & $\mathrm{Qb}$ & Qc & Qd & $\mathrm{Qe}$ & Qf \\
\hline \multicolumn{7}{|l|}{ Well-endowed } \\
\hline $\mathrm{A}(\mathrm{N}=70)$ & $29(41.4 \%)$ & $29(41.4 \%)$ & $4(5.7 \%)$ & $11(15.7 \%)$ & $15(21.4 \%)$ & $6(8.6 \%)$ \\
\hline $\mathrm{C}(\mathrm{N}=80)$ & $43(53.8 \%)$ & $55(68.8 \%)$ & $17(21.3 \%)$ & $51(63.8 \%)$ & $43(53.8 \%)$ & $12(15.0 \%)$ \\
\hline $\mathrm{D}(\mathrm{N}=55)$ & $32(58.2 \%)$ & $34(61.8 \%)$ & $10(18.2 \%)$ & $25(45.5 \%)$ & $26(47.3 \%)$ & $5(9.1 \%)$ \\
\hline Overall $(\mathrm{N}=205)$ & $104(50.7 \%)$ & $118(57.6 \%)$ & $31(15.1 \%)$ & $87(42.4 \%)$ & $84(41.0 \%)$ & $23(11.2 \%)$ \\
\hline \multicolumn{7}{|l|}{ Less-endowed } \\
\hline $\mathrm{B}(\mathrm{N}=30)$ & $5(16.7 \%)$ & $6(20.0 \%)$ & $4(13.3 \%)$ & $7(23.3 \%)$ & $7(23.3 \%)$ & $2(6.7 \%)$ \\
\hline $\mathrm{E}(\mathrm{N}=42)$ & $6(14.3 \%)$ & $7(16.7 \%)$ & $0(0.0 \%)$ & $2(4.8 \%)$ & $1(2.4 \%)$ & $1(2.4 \%)$ \\
\hline $\mathrm{F}(\mathrm{N}=35)$ & $11(31.4 \%)$ & $11(31.4 \%)$ & $1(2.9 \%)$ & $10(28.6 \%)$ & $6(17.1 \%)$ & $1(2.9 \%)$ \\
\hline $\mathrm{G}(\mathrm{N}=22)$ & $9(40.9 \%)$ & $14(63.6 \%)$ & $1(4.5 \%)$ & $3(13.6 \%)$ & $8(36.4 \%)$ & $0(0.0 \%)$ \\
\hline Overall $(\mathrm{N}=129)$ & $31(24.0 \%)$ & $38(29.5 \%)$ & $6(4.7 \%)$ & $22(17.1 \%)$ & $22(17.1 \%)$ & $4(3.1 \%)$ \\
\hline
\end{tabular}

Table 4

Independent samples T-Test analysis on performance of Well-endowed and Less-endowed schools on writing Chemical Formulae of Compounds

\begin{tabular}{llllllll}
\hline \multicolumn{1}{c}{ Schools } & $\mathrm{n}$ & Mean & $S D$ & $t$ & $d f$ & $p$ \\
\hline Well-endowed & 205 & 2.200 & 1.669 & 7.454 & 332 & $0.001^{*}$ \\
Less-endowed & 129 & 0.940 & 1.184 & & & \\
\hline
\end{tabular}

Note. Significant $p<0.05$

Generally, writing of chemical formulae was a problem to students from both well-endowed and less endowed schools. The chemical formula of the compound Copper (II) tetraoxophosphate (V) posed great difficulty to the students as only $15.1 \%$ of students from well-endowed schools compared to $4.7 \%$ of students from less-endowed schools answered it correctly. Surprisingly in school A, (well-endowed) less than one-sixteenth of the students answered this question correctly. None of the 42 students in school E (less-endowed) could answer this question. In schools F and G (less-endowed) only one student each could answer this question correctly. Writing the chemical formula for Silver nitride posed much greater difficulty to 
Students' understanding and difficulties in writing chemical formulae of inorganic compounds

the students as less than one-eighth of students from well-endowed schools and less than one-sixteenth of students from less-endowed schools could answer the this item correctly. No student from school $G$ (less-endowed) could answer this item correctly. In schools E and F only one student each could answer this item correctly. The performances of students in each compound are discussed below:

\subsection{Qa: Copper (I) oxide}

Out of 334 students who participated in the study, $40.4 \%$ could write the correct chemical formula of Copper (I) oxide as $\mathrm{Cu}_{2} \mathrm{O}$. From Table 3, 50.7\% out of 205 students from well-endowed schools wrote the correct chemical formula of the above compound. Also out of 129 students from less-endowed schools only $24.0 \%$ wrote the correct chemical formula of the compound. From Table 3, 59.6\% out of 334 students who took part in the study could not write the correct chemical formula of Copper (I) oxide. Students' responses and reasons for their inability are presented in Table 5.

Table 5

Students' responses and reasons for writing the Chemical Formula of Copper (I) oxide wrongly (N=199)

\begin{tabular}{clc}
\hline Chemical formula given by students & Students' reasons for the formula provided & Number and percentage of students \\
\hline $\mathrm{CuO}$ & Copper (I) is $\mathrm{Cu}$ and oxide is $\mathrm{O}$ & $120(60.3 \%)$ \\
$\mathrm{CuO}^{-}$ & Copper (I) is $\mathrm{Cu}^{+}$Oxide is $\mathrm{O}^{2-}$ & $50(25.1 \%)$ \\
$\mathrm{CuO}_{2}^{-}$ & Copper (I) is $\mathrm{Cu}^{-}$ & $29(14.6 \%)$ \\
\hline
\end{tabular}

The main difficulty on the part of the $59.6 \%$ of the students who could not write the chemical formula of Copper (I) oxide was their lack of understanding of the meaning of the Roman numeral in the bracket. They failed to see that the Roman numeral in the bracket is the valency of copper. They also failed to take into consideration the valency of oxygen which is two. The reasons given by majority of students who got the answer wrong showed that they did not understand the role valencies play in the writing of chemical formulae.

\subsection{Qb: Iron (II) sulphide}

Out of 334 students involved in the study, $46.7 \%$ was able to write the correct chemical formula of Iron (II) sulphide as FeS. From Table 3, 57.6\% out of 205 students from well-endowed schools wrote the correct chemical formula of the above compound. Also out of 129 students from less-endowed schools only $29.5 \%$ wrote the correct chemical formula of the compound. Hence from Table 3, a total of 53.3\% of students out of 334 students involved in the study could not write the correct chemical formula of Iron (II) sulphide. Their responses and reasons for this failure are presented in Table 6.

\section{Table 6}

Students' responses and reasons for writing the Chemical Formula of Iron (II) sulphide wrongly $(N=178)$

\begin{tabular}{llr}
\hline Chemical formula given by students & Students' reasons for the formula provided & Number and percentage of students \\
\hline $\mathrm{Fe}_{2} \mathrm{~S}$ & Iron (II) is $\mathrm{Fe}_{2}$ and Sulphide is $\mathrm{S}$ & $107(60.1 \%)$ \\
$\mathrm{Fe}\left(\mathrm{SO}_{3}\right)_{2}$ & Iron is Fe and sulphide is $\mathrm{SO}_{3}$ but & $38(21.3 \%)$ \\
& it is multiplied 2 because it is \\
& bonded to Iron (II) & \\
& Iron is Fe and sulphide is SO but it & $10(5.6 \%)$ \\
& is multiplied by 2 because it is \\
& bonded to Iron (II) & \\
& Iron is Fe and sulphide is S but it & \\
& is multiplied by 2 & $23(13.0 \%)$ \\
\end{tabular}


Baah, R. \& Anthony-Krueger, C.

The main difficulty on the part of the $53.3 \%$ of the students who could not write the chemical formula of Iron (II) sulphide was their lack of understanding of the meaning of the Roman numeral in the bracket. In addition, the correct formula of sulphide was a problem to $26.9 \%$ of those who could not write the correct chemical formula of Iron (II) sulphide.

\subsection{Qc: Copper (II) tetraoxophosphate (V)}

Only $11.1 \%$ of 334 students who participated in the study was able to write the correct chemical formula of Copper (II) tetraoxophosphate (V) as $\mathrm{Cu}_{3}\left(\mathrm{PO}_{4}\right)_{2}$. Of 205 students from well-endowed schools only $15.1 \%$ wrote the correct chemical formula of the compound. In the less-endowed schools only $4.7 \%$ wrote the correct chemical formula of the compound. Therefore an overall $88.9 \%$ could not write the correct chemical formula of Copper (II) tetraoxophosphate (V). Reasons given by these students for their wrong answers are presented in Table 7.

Table 7

Students' responses and reasons for writing the Chemical Formula of Copper (II) tetraoxophosphate (V) wrongly $(N=297)$

\begin{tabular}{clc}
\hline Chemical formula given by students & \multicolumn{1}{c}{ Students' reasons for the formula provided } & Number and percentage of students \\
\hline $\mathrm{CuPO}_{4}$ & $\begin{array}{l}\text { Copper (II) is } \mathrm{Cu}^{2+} \text { and } \\
\text { tetraoxophosphate }(\mathrm{V}) \text { ion is } \mathrm{PO}_{4}{ }^{2-}\end{array}$ & $165(55.6 \%)$ \\
& $\begin{array}{l}\text { Copper (II) is } \mathrm{Cu}^{2+} \\
\text { tetraoxophosphate }(\mathrm{V}) \text { ion is } \mathrm{PO}_{4}^{-}\end{array}$ & $70(23.6 \%)$ \\
& $\begin{array}{l}\text { Copper (II) is } \mathrm{Cu}_{2} \text { and } \\
\text { tetraoxophosphate }(\mathrm{V}) \text { is } \mathrm{PO}_{4} \\
\mathrm{Cu}_{2} \mathrm{PO}_{4}\end{array}$ & $42(14.1 \%)$ \\
$\mathrm{Cu}_{2} \mathrm{P}_{4}$ & $\begin{array}{l}\text { Copper (II) is } \mathrm{Cu}_{2} \\
\text { tetraoxophosphate }(\mathrm{V}) \text { is } \mathrm{P}_{4}\end{array}$ & $20(6.7 \%)$ \\
\hline
\end{tabular}

Almost $90 \%$ of the students who took part in the study could not write the chemical formula of Copper (II) tetraoxophosphate $(\mathrm{V})$ mainly because of

A. their lack of understanding of the meaning of the Roman numerals in the brackets and

B. their inability to write the correct chemical formula of tetraoxophosphate (V) ion.

\subsection{Qd: Calcium trioxonitrate (V)}

Out of 334 students who participated in the study, $32.6 \%$ was able to write the correct chemical formula of Calcium trioxonitrate $(\mathrm{V})$ as $\mathrm{Ca}\left(\mathrm{NO}_{3}\right)_{2}$. Out of 205 students from well-endowed schools, $42.4 \%$ wrote the correct chemical formula of the above compound with $17.1 \%$ of students from less-endowed schools writing the correct chemical formula of the compound. Hence an overall $67.4 \%$ of students who part in the study could not write the correct chemical formula of Calcium trioxonitrate $(\mathrm{V})$. Responses of students who got the chemical formula wrong and typical reasons assigned for writing the compound the way they did are presented in Table 8 .

The main difficulties on the part of the $67.4 \%$ of the students who could not write the chemical formula of Iron (II) sulphide were

A. use of wrong oxidation numbers of ions

B. inability to write the correct chemical formula of trioxonitrate (V) ion. 
Students' understanding and difficulties in writing chemical formulae of inorganic compounds

Table 8

Students' responses and reasons for writing the Chemical Formula of Calcium trioxonitrate (V) wrongly $(N=225)$

\begin{tabular}{|c|c|c|}
\hline Chemical formula given by students & Students' reasons for the formula provided & Number and percentage of students \\
\hline $\mathrm{CaNO}_{3}$ & $\begin{array}{l}\text { Calcium ion is } \mathrm{Ca}^{+} \text {and nitrate ion } \\
\text { is } \mathrm{NO}_{3}^{-}\end{array}$ & $141(62.7 \%)$ \\
\hline $\mathrm{Ca}(\mathrm{NO})_{2}$ & $\begin{array}{l}\text { Calcium ion is } \mathrm{Ca}^{2+} \text { and nitrate ion } \\
\text { is } \mathrm{NO}^{-}\end{array}$ & $30(13.3 \%)$ \\
\hline $\mathrm{Ca}_{3} \mathrm{~N}$ & $\begin{array}{l}\text { Calcium ion is } \mathrm{Ca}^{+} \text {and nitrate ion } \\
\text { is } \mathrm{N}^{3-}\end{array}$ & $30(13.3 \%)$ \\
\hline $\mathrm{Ca}_{3} \mathrm{~N}_{2}$ & $\begin{array}{l}\text { Calcium ion is } \mathrm{Ca}^{2+} \text { and nitrate ion } \\
\mathrm{N}^{3-}\end{array}$ & $24(10.7 \%)$ \\
\hline
\end{tabular}

\subsection{Qe: Ammonium trioxocarbonate (IV)}

Out of 334 students involved in the study, 31.7\% was able to write the correct chemical formula of Ammonium trioxocarbonate (IV) as $\left(\mathrm{NH}_{4}\right)_{2} \mathrm{CO}_{3}$. From Table 3, 41.0\% of students from well-endowed schools wrote the correct chemical formula of the compound and $17.1 \%$ out of 129 students from less-endowed schools also wrote the correct chemical formula of the compound. Therefore a total of $68.3 \%$ of students who participated in the study could not write the correct chemical formula of Ammonium trioxocarbonate (IV). Their reasons and responses that explain their inability are presented in Table 9.

\section{Table 9}

Students' responses and reasons for writing the Chemical Formula of Ammonium trioxocarbonate (IV) wrongly $(N=228)$

\begin{tabular}{|c|c|c|}
\hline Chemical formula given by students & Students' reasons for the formula provided & Number and percentage of students \\
\hline $\mathrm{NH}_{4} \mathrm{CO}_{3}$ & ammonium ion is $\mathrm{NH}_{4}^{+}$and & $114(50.0 \%)$ \\
\hline $\mathrm{NH}_{4}(\mathrm{CO})_{3}$ & $\begin{array}{l}\text { Carbonate ion is } \mathrm{CO}_{3}^{-} \\
\text {ammonium ion is } \mathrm{NH}_{4}^{+} \text {and } \\
\text { Carbonate ion is } \mathrm{CO}_{3}^{-}\end{array}$ & $51(22.4 \%)$ \\
\hline $\mathrm{NH}_{4} \mathrm{C}$ & ammonium ion is $\mathrm{NH}_{4}^{+}$and & $39(17.1 \%)$ \\
\hline $\mathrm{NH}_{4} \mathrm{CO}$ & $\begin{array}{l}\text { Carbonate ion is } \mathrm{C}^{-} \\
\text {ammonium ion is } \mathrm{NH}_{4}^{+} \text {and } \\
\text { Carbonate ion is } \mathrm{CO}^{-}\end{array}$ & $24(10.5 \%)$ \\
\hline
\end{tabular}

The main difficulties on the part of the $68.3 \%$ of the students who could not write the chemical formula of Ammonium carbonate were

A. their inability to write the correct formula of trioxocarbonate (IV) ion

B. wrong oxidation number of the trioxocarbonate (IV) ion used.

\subsection{Qf: Silver nitride}

Out of 334 students who took part in the study, only $8.1 \%$ was able to write the correct chemical formula of Silver nitride as $\mathrm{Ag}_{3} \mathrm{~N}$. Only $11.2 \%$ of students from well-endowed schools wrote the correct chemical formula of the compound and only $3.1 \%$ wrote the correct chemical formula of the compound. Not even one-fifth of students from any of the well-endowed schools and one-fourteenth of students from any of the less-endowed schools could write the correct chemical formula of Silver nitride. Hence an overall $91.9 \%$ of the students who 
Baah, R. \& Anthony-Krueger, C.

participated in the study could not write the correct chemical formula of Silver nitride. Their reasons for this failure are presented in Table 10.

\section{Table 10}

Students' responses and reasons for writing the Chemical Formula of Silver nitride (IV) wrongly (N=307)

\begin{tabular}{clc}
\hline Chemical formula given by students & Students' reasons for the formula provided & Number and percentage of students \\
\hline $\mathrm{AgNO}_{3}$ & $\begin{array}{l}\text { Silver ion is } \mathrm{Ag}^{+} \text {and nitride ion is } \\
\mathrm{NO}_{3}^{-}\end{array}$ & $92(30.0 \%)$ \\
& $\begin{array}{l}\text { Silver ion is } \mathrm{Ag}^{+} \text {and nitride ion is } \\
\mathrm{AgN}_{3}\end{array}$ & $\begin{array}{l}\mathrm{N}^{3-} \\
\mathrm{AgNO}_{2}\end{array}$ \\
& $\begin{array}{l}\text { Silver ion is } \mathrm{Ag}^{+} \text {and nitride ion is } \\
\mathrm{NO}_{2}^{-} \\
\mathrm{SiN}\end{array}$ & $50(16.0 \%)$ \\
& $\mathrm{Silver}$ ion is $\mathrm{Si}^{+}$and nitride ion is \\
& $\mathrm{N}^{-}$ & $76(24.8 \%)$ \\
\end{tabular}

The main difficulties on the part of the $91.9 \%$ of the students who could not write the correct chemical formula of Silver nitride were

A. their inability to write the correct formula of nitride ion and

B. their inability to write the correct symbol of Silver atom.

\section{Conclusions}

The study found that the problem SSS 3 elective science students have in writing chemical formulae are:

A. Students do not understand the meaning of Roman numerals that are put in brackets of IUPAC names. Examples Iron (II) sulphide was written as $\mathrm{FeS}_{2}$. Also in the same compound, Iron was written as $\mathrm{Fe}_{2}$, in Copper (II) tetraoxophosphate (V), Copper was written as $\mathrm{Cu}_{2}$ etc.

B. Students have problem with what valencies are and do not understand the role they play in writing of chemical formulae.

C. Writing the correct formula of some radicals and some ions is also a problem to the students. Examples sulphide was written as $\mathrm{SO}_{3}$ and $\mathrm{SO}$, tetraoxophosphate $(\mathrm{V})$ ion as $\mathrm{PO}_{4}{ }^{2-}, \mathrm{PO}_{4}^{-}, \mathrm{P}_{4}$, Nitride ion as $\mathrm{NO}_{3}{ }^{-}, \mathrm{NO}^{-}$trioxocarbonate (IV) ion as $\mathrm{CO}_{3}{ }^{-}$etc.

D. Combination of some cations and anions to form neutral compounds is a big problem to the students due to the problem they have with valency.

E. The correct names of some radicals are a problem to students.

F. Tetraoxophosphate (V) ion and the nitride ion are not familiar to the students.

The results of the hypothesis tested also indicated that students from less-endowed schools have much difficulty in writing chemical formulae than students from well-endowed schools.

\section{Implication for Research and Practice}

The findings from this study point to the fact that students from both well-endowed and less-endowed secondary schools have difficulty in writing chemical formulae of inorganic compounds from IUPAC names with the problem being more prevalent in less-endowed schools. Chemistry teachers therefore need to employ innovative teaching strategies to help students on how the formulae are arrived at as it would also help the 
Students' understanding and difficulties in writing chemical formulae of inorganic compounds

students to avoid rote learning of formulae of compounds. Teachers should pay particular attention to this area of chemistry as it could attract a lot of beginners to the subject. It also became clear in the study that students' major problem hindering them from writing correct chemical formulae is their lack of knowledge of valency and the role it play in writing of chemical formulae. A research could therefore be conducted to find out the reason behind.

\section{References:}

Anamuah-Mensah, J., \& Apafo, N.T. (1986). Students perceived difficulties with ordinary level chemistry topics. Chemistry and Industry Proceedings, 1(1), 38-39.

Hines, C. (1990). Students' understanding of chemical equations in secondary schools in Botswana. School Science Review, 72(285), 138-140.

Johnstone, A. H., Morrison, T. I., \& Sharp, D. W. A. (1976). Topic difficulties in chemistry. Education in Chemistry, 20, 212-218.

Lazonby, J. N., Morris, J. E., \& Waddington, D. J. (1982). The muddle some mole. Education in Chemistry, 19, 109-111.

Savoy, L. G. (1988). Balancing chemical equations. School Science Review, 69(249), 713-720.

West African Examinations Council. (1994). Chief examiners' report, SSSCE, Nov-Dec, Accra, Ghana.

West African Examinations Council. (2001). Chief examiners' report, SSSCE, Nov-Dec, Accra, Ghana.

West African Examinations Council. (2004). Chief examiners' report, SSSCE, Nov-Dec, Accra, Ghana.

West African Examinations Council. (2005 ). Chief examiners' report, SSSCE, Nov-Dec, Accra, Ghana. 
Baah, R. \& Anthony-Krueger, C. 